year 6. Although statistically significant, all of these changes were small. No significant effect of gender on attitudes or attitudinal change was found.

Conclusion Medical students' attitudes towards their future role in EOLC were broadly positive. Core science was associated with increasingly negative attitudes and clinical studies with increasingly positive attitudes. For teaching faculty, the challenge remains to address negative and foster positive attitudes towards EOLC during medical school.

\section{P 053 MEDICAL STUDENTS' ATTITIDES TO END OF LIFE CARE THROUGHOUT THEIR COURSE}

Stephen Barclay, Pia Thiemann, Richard Parker, Rebecca Whyte, John Benson, Diana Wood, Thelma Quince. School of Clinical Medicine, University of Cambridge, Cambridge, UK

10.1136/bmjspcare-2014-000654.94

Background Medical student End of Life Care (EOLC) education is increasingly recognised as important. Knowledge concerning drugs and services can be readily taught and skills of communicating with patients and families are increasingly addressed. Attitudes towards EOLC are important as they influence behaviour in clinical practice.

Aims To examine medical students' attitudes to EOLC in each year of their course

To investigate change in these attitudes over time during their course

To identify gender differences in attitudes and attitudinal change.

Methods Questionnaire administered to four cohorts of core science and clinical medical students at the University of Cambridge Medical School in 2007 to 2010, with longitudinal follow-up in subsequent years; 1027 participants in total. Students indicated their agreement towards 8 EOLC statements on five-point Likert scales, based on Sullivan's US study.

Results Students started their course with broadly positive attitudes (towards the doctor's responsibility, psychological aspects for patients and personal impact) which largely persisted into the final years. During core science some attitudes became more negative, whereas during clinical studies some attitudes became more positive. Analysis of a subsample of 55 students for whom 6 year longitudinal data were available revealed significant positive change regarding the doctor's responsibility from year 1 to 